\title{
The Contemporary Enlightenment of Shaw Brothers’ Historical and Swordsman Films’ Communication
}

\author{
RAN Hua \\ Southwest University of Political Science and Law, Chongqing, China
}

\begin{abstract}
Shaw Brothers (Hong Kong) Limited and its films have a wide range of influence around the world. In the contemporary era, the communication of the Shaw costume films, emphasises the humanity's classical appeal and invisible revival motivation. Also, it puts great emphasis on the trend from heroic monologue to discourse equality. The essay focuses on the aesthetic style and cultural connotation of the costume swordsman martial arts films directed by Zhang Che and Chu Yuan, revealing how the combination of the cultural psychology and Shaw's management model have jointly accomplished Shaw's films' glorious time for decades in Hong Kong. Furthermore, it proves that how the cultural mentality of the martial arts "King of the Forerunner" has affected the transformation and development of Shaw Brothers, and how the status of costume martial arts films were changed in contemporary communication.
\end{abstract}

Keywords: Shaw Brothers’ films, costume swordsmen, Zhang Che, Chu Yuan, contemporary communication, enlightenment

The contemporary enlightenment of Shaw Brothers' historical and swordsman films' communication will be the key discussion. Shaw Brothers Limited (hereinafter referred to as "Shaw"), whose President is Sir Run Run Shaw, was established in 1958. From 1959 to 1979, Shaw stood out among many film companies such as Cathay, Great Wall Movie Enterprises and so on, and finally became the largest producer in Hong Kong. For the sake of narrative, this article starts from the films directed by Zhang Che and Chu Yuan and their aesthetic styles. By analyzing it, we could have a better understanding of the development of Shaw's costume martial arts films and summarize the contemporary enlightenment of their dissemination. Zhang Che (1923-2002), whose real name was Zhang Yi yang and pen name, He Guan, was born in Qing tian, Zhejiang province with representative works including Sword With One Arm, Revenge and Horse Stabbing. Chu Yuan (1934--), formerly known as Zhang Shijian, used Qin Yu as his pseudonym. Being a native of Meixian county, Guangdong province, he joined the "Shaw" as a director in 1972, with works including Killer Clans and Chu Liu Xiang.

\section{Why Shaw Costume Martial Arts Films Became the Center of Discussion}

From the development of Shaw, Shaw's costume martial arts films are mainly composed of the new martial arts films founded by Zhang Che and King Hu, and the literary martial arts films directed by Chu Yuan and Dillon.

RAN Hua, Ph.D. of Literature, Lecturer, School of Global Journalism and Communication, Southwest University of Political Science and Law, Chongqing, China. 
As for the reason why Shaw costume martial arts films could become the center of the topic, there are many explanations which are concentrated in the following aspects.

Firstly, Shaw Brothers Limited and its films have a wide range of influence around the world. It is worth mentioning that Shaw's film production system has considerable superiorities. "Shaw's company has set up a large-scale film-making enterprise, which has monopolized the Hong Kong film industry for more than 20 years with its powerful strength, fully demonstrating its superiority and management ability” (Liu, 2005, p. 183). Shaw has monopolized the film industry in Hong Kong no less than 20 years, especially the first 10 years which was the golden age at high levels of output relying on a strong lineup of famous stars, well known directors and big productions. Shaw's company had more than 1,000 films in last 30 years, which was enormous and rare in the history of world film and television. The Shaw also has a high standard of quality guarantee, just as described in its advertisement, "Shaw's films, must be boutique". Since "the martial arts landscape is the common experience of the nation, and the martial arts imagination has become a unique mass entertainment transmitting through the film media” (Liu, 2014, p. 17). Shaw's film not only has a good reputation in ethnic Chinese, but also becomes a landmark in the history of world film. In addition, it has gradually become a symbol for imaginative culture of China and an important carrier of global cultural communication.

Secondly, Shaw's costume martial arts films make up a large part of Shaw's films, with plenty of representative works. In 2000, Hong Kong Celestial Pictures obtained the permanent copyright of 760 films of Shaw Brothers, of which action martial arts films accounted for 37.7\%. Meanwhile, Shaw's costume martial arts film also has its representative works. Shaw's began to create inspired by the concept of the colorized new martial arts film. Among them, the most eminent representative works are King Hu's Drunken Man and the One-Armed Knife directed by Zhang Che in 1967. King Hu's Drunken Man quickly confirmed the status of the new martial arts film after absorbing the essence of Cantonese films. One-Armed Knife starred by Wang Yu, Pan Yingzi and others, broke a million in the box office in that year. Undoubtedly, it was all the rage. Drunken Man changed the form of Chinese martial arts film, while One-Armed Knife gave a new spirit of the times, and they were known as the iconic two flags. In addition, the Shaw costume martial arts films are a link between the preceding and the following, because they were born in the crisis of Huang Mei opera directed by Li Hanxiang, and then began the creation of literary martial arts films, boxing kicks, and effects-driven martial arts films, which have an important transformation significance in the development of Shaw films, and also this is the reason why we study the Shaw's costume martial arts films.

Thirdly, Shaw's company has lots of outstanding figures in martial arts films. The most important of all film producers are Sir Run Run Shaw, Zhang Che, King Hu, Chu Yuan, Dillon, etc. Who are outstanding people and have played a vital role in the film industry. In the book Hong Kong Film Romance, Mr. Shaw's historical status, decision-making operation modes, and world vision were recognized and praised by famous film critic Wei Junzi despite the relationship between the Shaw's hegemonic film policy and the run model of Sir Run Run Shaw's hegemony still deserves further discussion. In short, Shaw's success has benefited from the unique cultural character and cultural understanding of Sir Run Run Shaw and Zhang Che. After a short period of cooperation with Shaw Brothers Film Company, King Hu went to Taiwan for a further development. Zhang Che and his four generations of disciplesonce became the nucleus of the Shaw's martial arts films. In the 1970s, the powerful triangle, Gu Long, Chu Yuan, and Dillon appeared, leading the Shaw's costume swordsman martial arts movies 
into a flourishing era. A unique era in the film history was realized by those talented heroes.

Lastly, the digital technology enabled Shaw's costume martial arts films to be restored and preserved. Shaw's martial arts films were mostly adapted from Gu Long and other writers' martial arts novels, which were successful examples of cross-media communication. In mainland China, Shaw's costume martial arts films have been widely disseminated on websites such as Youku, Iqiyi, Tencent Video, etc., and provincial satellite TVs such as Liaoning TV and Guangdong TV are also broadcasting Shaw's martial arts movies and TV shows. In terms of technology, Celestial Pictures not only obtained the permanent copyright of 760 Shaw Brothers films, but also spent 200 million yuan to restore these films. The protection of copyright and the restoration of technology have enabled Shaw to gain an opportunity to spread in the new media era. The mass media in the era successfully made Shaw's costume martial arts films a type of film with unique temperament. Although it is only partially influential, non-mainstream type of communication, it would never be a shortage of fans, some of who are crazy and are comparable to the hero of a movie, whose strength cannot be underestimated.

All those mentioned reasons are why we discuss and attach great importance to the Shaw costumes martial arts films.

\section{The Positive Enlightenment of Shaw's Costumes Communication}

Shaw's costume martial arts films have become a symbol for imagining and understanding Chinese culture and their successful communication has many positive revelations.

In the contemporary era, the communication of the Shaw costume films highlights the humanity's classical appeal and invisible revival motivation. "The costume martial arts films" is a compound word. As a social concept, it has both forward parts and backward factors. "Ancient costume" is to dress up in a restored ancient way that has been transformed by modern people, which tries to obtain the appearance characteristics of the ancient and their hints. Ancient costume also has its metaphorical component, that is, "the medium is speculation", which reminds people that there is a rich sub-media space under the surface of "the ancient costume" worthy of discussion. It reflects that the psychological expectation of people to renovate and revive the ancient things, which is the value embodiment of people's classical pursuit. Moreover, the ancient martial arts films contain the resurrection consciousness and revival power for classic. In these martial arts films, there are no less than hundreds of weapons. Swords and other weapons are not only the weapons used by the characters in the film, but also served as the tool in the process of film shooting which can both reflect the characters' plain and sedate personality, and slowly and distinctive rhythms in the film, and specifically reflected the development from the cold weapon to the hot violence. Weapons, such as swords, and costumes are specific symbols. As media, they are the antennas that humans move forward, which are toward classic. The revival consciousness which is selected, judged and finally identified by contemporary people from the mainstream and traditional culture, is hidden incurrent popular and consumer culture. There are specific performances of these in King Hu and Chu Yuan's films. Researchers hold that "it is the cinematic utilization and transformation of the aesthetic elements in traditionalopera” (Liu \& Tao, 2013, p. 16), which constitutes its uniqueness of King Hu's martial arts movies. Chu Yuan's films also show this characteristic. In 1976, the film Killer Clans directed by Chu Yuan, which symbolized "killer, love, and fame", meant a kind of motivation of resurrection. In a word, the positive enlightenment of Shaw's costumes communication is to publicize the repressed classical spirit and feelings, and 
activate the revival power in the traditional culture. What's more, it emphasizes the reappearance of the heroes and the spirit of swordsmen. "These martial arts films are not simply action films, but relive the figure of previous heroes in people's minds through new techniques" (Wang, 2006, p. 114). Specifically, the communication of Shaw's costume martial arts films naturally reveal its inner logic: explore the original motivation of social development in the logical chain of putting more emphasis on "friendship" rather than "profits" and under the framework of "classical sentiments" and "social dynamics".

The communication of Shaw's costume martial arts films also displays the trend from heroic monologue to discourse affirmation and the former is the typical feature of Shaw's costume martial arts films. In the first place, the hero in film is masculine and aggressive. Zhang Che is extremely good at creating such masculine works with his all creations having never "changed the traits of masculine martial arts" (Jia, 2005, p. 203) and the Pangu Wars is one of the most classic representative works. In the second place, there exists a unique sad experience. Based on a single hero, the film's essence is the growth of male heroes by mainly telling how the heroes were born, to be a swordsman and showing the qualities of heroes, and be chivalric. The films directed by Chu Yuan are quite typical that "he reveals a homeless orphan complex and wandering consciousness of the protagonists through their unique backgrounds and different spiritual temperaments, and expresses an inner tragic experience in the quest for their self-identity” ( $\mathrm{Li}, 2005$, p. 344). Then, the aggressive hero must have a huge encumbrance. It is the fate itself that promotes the plot of the film. The hero goes through sufferings by all kinds of tribulations. An aggressive and lonely hero encounters ups and downs, helpless. It seems that the individual hero has his subject. Nevertheless, the fact is that the individual is to digest and deconstruct himself. "It break the so-called unbreakable myth that the martial arts protagonist would never die when the first time a film's protagonist died arranged by Zhang Che” (Jia, 2005, p. 203); Later, the protagonist Wang Yu actually died in every film, which made heroes die for the cause of righteousness a new classic model in martial arts films. The protagonist's death or inevitability of death prove the helplessness of the hero. Finally, the image of the protagonist has become every "small potato". Chu Yuan is good at shaping the character of the common people and he has transformed the evolution of the hero's model of "a single big shot” in Zhang Che's films. For example, those "who have no desire", like the servant, the master, the thief, the assassin, the killer... "They who often left a deep impression on the audience though in a few minutes, together with the heroes, forming the heroic spectrum in Chu Yuan's martial artsworks" (Zhang, 2006, p. 31). They conspicuously wandered in film world, leaving such an indelible mark and became an essential part of it. With transition from Zhang Che to Chu Yuan and Gu Long, the trend made a great difference. Zhang Che's style is quite simple, straightforward and difficult to be interpreted, but the protagonist is easy to die, and the death of the protagonist actually is the start of rebuilding some small characters, which is a transition trend from heroic monologue to discourse affirmation. This kind of intentional reflection and positive diversion, is actually a concept of discourse affirmation and modern democracy.

The costume martial arts films' huge breakthrough on the theme of traditional martial arts films, or the reflection and criticism of chivalrous righteousness, hatred, fighting, hegemony are new actual and aesthetic demands of audiences for martial arts films in the contemporary legal society. This is another positive significant aspect of Shaw's costume martial arts films. (Pan, 2006, p. 54)

What we advocate is that an appropriate ethical awareness and communication philosophy, namely, some audience's obsession should be respected; and the parting classical aesthetic tradition should be well maintained. 
However, it should be equally alert that sword martial arts films can neither be used as a dump of emotion for backward thoughts nor the carrier of social contradictions and an excuse or burden for social civilization or progress.

\section{Cultural Caution of the Communication of Shaw's Costume Martial Arts Films}

The character of the filmmaker and his business strategy has a tremendous impact on the development of the culture industry. As is well known, the rise and fall of Shaw's martial arts films are closely related to the cultural character of Shaw's filmmakers. From the good side, Sir Run Run Shaw has world insight, and can finish transcendental decision-making operation modes. His cultural character makes his strong leadership, but the shortage are his overbearing leadership patterns. As for Zhang Che, excepting for his many virtues, there are also defects in his character. He understood tactics and worldly wisdom well, being deeply sensitive to art but less to utility. He compared himself to Chen Sheng and Wu Guang, "Although each film starts with me, it is often not me who do the best. I always play the role of 'the pioneer of the king”” (Wei, 2010, p. 164). He often feels sad about "being willing to try, but powerless in creation". Reflected in the film, there are more men and less women, a smaller proportion of love, and stressing on a fraternal feeling of brothers, male friendship, which unconsciously exudes a sense of male power. Even if the movie Golden Swallow (1968), featuring the female hero XieRuyan, was still "the object projected by male desire". He only pursues masculinity rather than femininity, which is stubbornly abstinent. "He is always in danger, therefore he is bellicose, aggressive, and brave" (Li, 2005, p. 366). In short, Sir Run Run Shaw's management style is as tough as Zhang Che's cultural character, both of which are beneficial to participate in competition in a dangerous and tough environment, but create a sole style orientation that is inflexible and irreconcilable. Contradictions within groups and industries have been exposed, and personnel conflicts have also provoked the transformation from friends into enemies, thus brought unexpected difficulties to its development. For example, Zou Wenhuai, who founded his company himself, Li Hanxiang, who went to Taiwan to seek for further development, and even Zhang Che's leaving to Taiwan is also related to this. Such a state is similar to the fate of the martial arts heroes they created. The mentality of "being a king and pioneer" combines the domination and arrogance of the king and the drive of the pioneer, which brings about the power of progress but leads a state of powerlessness that lacks stamina in creation. In fact, what can't be concealed is the anxiety of "losing power and status", covered by brave struggles. Such dynamic psychology has been realized by researchers in Zhang Che's works. From one-armed knife to one-armed knife king, Zhang Che also questioned and reflected himself on violence, which is powerless. "This may be ruthless 'correction' and 'adaptation' of individual subjective will by the film industry in a special social and historical environment; and this may be the dual identity of both the 'author' and the 'protagonist' in the film Zhang Che has played." Just as the movie The Web of Death (directed by Chu Yuan, and starred by Jing Li and Yue Hua in 1976) said, "let it bleed to death”. The firm determination of the creator is unavoidably capricious and sad. However, the swordsmen just reveal the philosophy of righteousness of life and death under the classical memory and are exactly driven by it while cultural panic and anxiety will put them in a state of horror, which may not be positive or beneficial for the operation and management of culture industries.

Nowadays, in an era of mass media communication, the state of amusing to death weakens the rational thinking and discriminating ability of modern humans. The public knows little about the operation within the 
industry and the ethical relationship near at hand. And the audiences lack basic understanding and sympathy for the creators who are facing a two-sided conundrum. All of these will make the creator passively trapped in the desperate situation, and the psychology will also affect the health of the industry. Therefore, the audiences' attitude toward the backward consciousness, the expectation for a better life, and the persistence of the democratic concept cannot obtain sustenance in the costume movies, which widen distance between the audience and the costume martial arts films. In view of this, we should be vigilant the dissipation of cultural dynamics from both the creators and the audiences. In addition, in the process of cultural industrialization, it is necessary to be wary of managers' excessively arbitrary management mode and the sad experience of industrial operators and managers should be effectively released, and the obstacles that cannot be communicated between cultural economization and economic culturalization should be quickly eliminated. At the same time, it is also essential to understand that in the course of the development of film culture, we must reflect on the issue of "cultural communication" and then cultural practice whenever cultural communication encounters difficulties. The path "from cultural communication dilemma to reflection on the issues of communication of culture, and then returning to cultural practice” is not only the cultural warnings for the contemporaries that given by opposing communication of Shaw's costume martial arts films, but also should be the subject of the era in the development of contemporary cultural industry.

We can draw the following revelation by thinking the communication of the martial arts films of Shaw: firstly, "films are influenced by historical background". Shaw and its costume martial arts films' status have the representative meaning of an era. It catches the audiences' eyes in a fierce and firm way, forming a male-narrative style, but its excessive patriarchal thinking pattern should be abandoned. In the fierce collisions between life and death, righteousness and evil, justice and injustice, blood and tears, completeness and deficiency, swordsmenare also deeply entangled in the anxiety of "losing power". Arbitrary actions and self-consumption not only suppress the growth of heroes, but also inhibit the diversified growth of human nature. Therefore, it should be reflected. Secondly, Shaw's costume swordsmanship martial arts films are given to martial arts action films. From fighting in various sword tools to the hand-to-hand combat, it is not only the normal logic of film development, but also in connection with the enlightenment of human self-awareness and body consciousness. The trend from simple tools to humanistic rational value, demonstrated positive significations. Thirdly, from Zhang Che to Chu Yuan, and then other action kung fu films, movie heroes had changed from the heroic monologue mode and the heroic position to the narrativeposition of the common people, indicating that the social mentality is changing correspondingly. Accordingly, they are the discovery of human beings, the stretch of the spirit of subject in individuals, and the affirmation of the value of themselves. To some extent, it reflects the historicalfacts of the contemporary society's progress from the heroic monologue mode to the discourse affirmative. With the development of social civilization and the concept of the rule of law, real appropriate value rationality and positive communication that we advocate are no longer to indulge in "violence and bloodiness", but to help them get rid of the obsolete consciousness of "death in anger and destroyed by violence", and enjoy the civilization of the present era, plan and implement future dreams, and will not smear all the good memories of the past.

\section{References}

Grois, B. (2014). The media is speculation. Nanjing: Nanjing University Press. 
Jia, L. L. (2005). History of Chinese martial arts films. Beijing: Culture and Art Publishing House.

Liu, H. (2005). Analysis of the system of Shaw Brothers (Hong Kong) Company's large film production plan. Film Art, 6, 183.

Liu, Y. R. (2014). On the martial arts film and the national imagination community. Film Literature, $23,17$.

Liu, Y. Q., \& Tao, H. X. (2013). The aesthetics of drama in Hu Jinqi’s martial arts films. Film Review, 8.

Li, Da. X. (2005). History of Chinese film culture. Beijing: Peking University Press.

Li, D. Y. (2005). A century of Chinese cinema 1905-1976. Beijing: China Radio and TV Press.

Pan, J. (2006). Going out of the swordsmen's dream—From the one-armed knife and new one-armed knife to see the creation trend of Shaw's martial arts films. Journal of Shanghai University (Social Science Edition), 5, 54.

Su, T. (2012). Gender, power and cultural imagination—On females in Shaw's martial arts films. Journal of Beijing Film Academy, 2.

Wu, H. (2004). Swordsman·kung fu films. Sanlian Bookstore (Hong Kong) Co., Ltd.

Wei, J. Z. (2010). Hong Kong films romance. Beijing: Culture and Art Publishing House.

Wang, H. Z. (2006). Shaw's Martial arts new century in Chinese films in the past 100 years. Film Art, 4, 14.

Zhang, X. (2006). The author in the type-The study of Chu Yuan's martial arts films. Film Art, 4, 31. 